\title{
How to Optimize the Relationship Between Public Spending and Happiness
}

\author{
Renaud Gaucher ${ }^{1}$ (D)
}

Received: 16 July 2020 / Accepted: 28 June 2021 / Published online: 13 July 2021

(c) The Author(s) 2021

\begin{abstract}
Happiness and efficient public spending are considered to be two desirable goals. In this paper, I consider happiness in the sense of how much one likes the life one leads (Veenhoven, 1984), and emphasize negative utilitarianism (Popper, 1952) as the best approach for promoting happiness in public policies. An ethical framework about public policies implemented to improve social conditions for happiness is suggested. I give a definition of the term optimization and propose two methods to optimize the relationship between public spending and social conditions for happiness. I briefly introduce a bookkeeping method, and I then present the bases of an econometric method in which quantile regression is described as the best tool within the negative utilitarianist approach, because quantile regression makes possible to know which independent variables influence most the degree of happiness of the least happy/ the saddest. The bookkeeping and the econometric methods presented are useful for any local, regional, national or supranational authority. These methods may also be useful for optimizing the relationship between natural resources consumption and social conditions for happiness. The paper is a conceptual paper.
\end{abstract}

Keywords Happiness · Public finance · Optimization · Negative utilitarianism · Public policy $\cdot$ Quantile regression

\section{Introduction}

Happiness and efficient public spending are two desirable goals. Happiness is important for at least four reasons. One: we prefer to be happy and, better, to be very happy (Adler et al., 2017). Two: happiness is humanizing. I use this adjective to highlight the fact that happiness is simultaneously a cause and a consequence of pro-social behaviours (Aknin et al., 2018). Happiness is a means to build a more

Renaud Gaucher

renaudgaucher@gmail.com

1 Erasmus Happiness Research Organization, Erasmus University Rotterdam, Burg. Oudlaan 50, Van der Goot Building, M5-43, 3062 PA Rotterdam, The Netherlands 
harmonious society. Three: happiness is a landmark that tells us to what extent a society works well. Four: happiness in individuals can be increased long-term (Veenhoven \& Hagerty, 2006). Happiness would not be interesting in public policies if it was impossible, even only difficult, to improve it lastingly. Efficient public spending is important for at least two reasons. One: we live in a world of scarcity and this scarcity may grow with increasing ecological constraints (Hickel \& Kallis, 2020). Two: people have more confidence in an authority when they perceive that this authority spends money efficiently and for their good (Kirchler, 2007).

My purpose is to propose methods to optimize the relationship between public spending and happiness. These methods are useful for any local, regional, national or supranational authority. Researchers can improve and develop these methods. I consider these methods can form the basis of further developments in this field. In my perspective, social sciences have to be scientifically relevant, and socially relevant. A goal of research in social sciences is to help build a better/less bad world.

This paper is divided into three parts. The first part concerns happiness, the second happiness policies and in the last part I explain a set of ideas on how to optimize the relationship between public spending and happiness.

\section{Happiness}

\section{Defining Happiness}

Philosophers have debated happiness at least since the times of the classical Greek philosophers, and we have inherited from these Greek philosophers two main perspectives: hedonism and eudaimonia. Hedonism is associated with two figures: Aristippus of Cyrene and Epicurus. We have lost the writing of Aristippus, but a lot of anecdotes exist in which his teaching and his life are characterized by enjoyment of the present time, freedom and contempt for the superfluous. Epicurus considers that pleasure is what makes one's life happy. What gives pleasure is good, what gives pain is bad. In Epicurus's perspective, desires have to be controlled and this control requires self-awareness and knowledge of the desires. Epicurus's perspective is therefore a form of asceticism (McMahon, 2006).

Eudaimonia is linked today with Aristotle's perspective on life, although other philosophical schools with different perspectives also used the concept of eudaimonia (Haybron, 2008). Aristotle considers that happiness is the ultimate goal, and that it can only be assessed over an entire life, not over a succession of moments. Happiness lies not only in pleasure, but also in the cultivation of virtue. Aristotle considers that human happiness is secondary, and that real happiness is the domain of gods (McMahon, 2006).

Hedonism and eudaimonia are not the only traditions on happiness stemming from Ancient Greece. For example, stoicism is on happiness and philosophers from this philosophical school consider that emotions lead to unhappiness and should be controlled (McMahon, 2006). Today, hedonism and eudaimonia from the Aristotle's perspective are the two movements that have the strongest influence on social scientists. 
Social scientists define happiness in various ways. In the hedonic perspective, the most used model is the subjective well-being (SWB) model. Several definitions of SWB exist. Diener (1984) proposes that SWB has three distinct components, life satisfaction (LS), positive affect (PA), and negative affect (NA), while Diener et al., (1999) include satisfaction in specific life domains, that is domain satisfaction (DS), in the definition of SWB.

Veenhoven (1984) reviewed the definitions of happiness in common, philosophical and modern social science languages, concluding that the best definition of happiness is the degree to which an individual judges the overall quality of his or her life-as-a-whole favourably. Veenhoven (1984) specifies each term of his definition. He also gives a short version of his definition of happiness: how much one likes the life one leads. To Veenhoven (1984), happiness has two components, two sources of information: the hedonic tonality of affect, that is the degree to which various affects that someone experiences are pleasant in character, and contentment, that is the degree to which an individual perceives his/her aspirations are met. Research suggests that hedonic level of affect dominates in the overall evaluation (Kainulainen et al., 2018).

Kahneman (1999) proposes the model of objective happiness. In this model, happiness is described as the average of instant utility over a period of time. Utility can be defined as a flow of positive and negative emotions and instant utility as the utility experienced at a time t. Kahneman's definition is an actualization of Bentham's (1789/1948) definition of happiness in which happiness is defined as 'the sum of pleasures and pains'. Kahneman et al. (1997) distinguish between experienced utility and remembered utility. This is explained by the fact that memory has some bias such as duration neglect and the overweight we can give to emotional and recent events. Thus, happiness as we remember it can be significatively different from happiness as we experience it.

Researchers have also developed eudaimonic and hybrid models of happiness, hybrid models being a mix of eudaimonic and hedonic components. The main model used in eudaimonic psychology is Ryff's model of psychological well-being (Ryff, 1989). It consists of 6 dimensions: self-acceptance, positive relations with others, autonomy, environmental mastery, purpose in life, and personal growth. Ryff (1989) does not use the word happiness to present her model, but she includes her model in positive functioning and eudaimonia.

Each model described above is considered to be relevant by some researchers, but my personal choice is to use the short version of Veenhoven's (1984) definition of happiness: how much one likes the life one leads. That is the more a person likes the life they lead, the happier they are, and the more a person dislikes the life they lead, the unhappier they are.

In my opinion, hedonic definitions of happiness have a strong advantage over eudaimonic definitions of happiness in that hedonic definitions respect the liberty of each one of us by not imposing on us an image of what a happy life should be. Two people may have the same degree of happiness in the hedonic perspective, but what makes these people reach the same degree of happiness can be different. There is no ideological notions of what a good life should be as there is in eudaimonic definitions. 
Among the hedonic definitions of happiness, the short version of Veenhoven's definition, liking the life one leads, seems to me the most interesting. The main reason to support this statement is that we want to like the life we lead and, when we have children or grandchildren, we want them to like the life they lead. Would you prefer to hate your life and to have children and grandchildren who hate their life ? Another advantage is that the short version of Veenhoven's definition can be summarized in a few simple words, which makes it easy to use as an empowerment tool for our lives.

In my opinion, there are other reasons to preferably use this definition. Unlike Kahneman's objective happiness, Veenhoven's definition is a stable definition of happiness, our degree of happiness does not evolve at each temporary modification of our emotional state. Unlike the SWB model, Veenhoven's definition is a one-dimension definition rather than a list that can be difficult to delineate when it comes to choosing a list of positive and negative affects and a list of domain satisfactions.

\section{Why Happiness is Socially Important}

Happiness is socially important for at least 4 reasons. One, most human beings want to like the life they live (Adler et al., 2017; Diener et al., 2000), and if they have children, it is likely that most parents want their children to like the life they lead. I have to recognize, however, that societies that glorify suffering have existed (Veenhoven, 2010) and collective cultures do not value happiness as much as individualistic cultures do (Diener et al., 2000).

Two, happiness is a hallmark of a society that works well. A society in which many people like the life they lead and few people do not is a better society than one with a lot of people who do not like the life they live and a few people do. This reasoning should last even if the difference in happiness between the two societies is smaller. All other things being equal, if we value happiness and compare a society where $90 \%$ of the people are happy and $10 \%$ are unhappy with a society where $80 \%$ of the people are happy and $20 \%$ are unhappy, it is likely that we will consider the first society to be better.

Three, happiness is humanizing: by using the term humanizing, I want to highlight the fact that happiness has the advantage, to a great extent, of uniting the improvement of our personal lives and the development of a more harmonious society. Happiness is good for people since we like being happy and very often it results in individual positive outcomes (Lyubomirsky et al., 2005). At the same time, our happiness is good for others, because pro-social behaviours are the causes and consequences of happiness (Aknin et al., 2018; Post, 2005).

Four, happiness can be lastingly increased. If happiness could not be increased longterm, we would not have effective actions and happiness would only be a scientific topic with no bearing on reality (Veenhoven \& Hagerty, 2006).

\section{Measurement of Happiness}

The first and most important feature of a good measure of happiness is that the measure fits with the theoretical framework it falls within. As I have chosen the 
short version of Veenhoven's definition of happiness, how much one likes the life one leads, as the best definition of happiness, a good measure can be 'How much do you like the life you lead?'.

Psychologists usually prefer to use scales with more than one item because they consider the psychometric properties of multi-item scales to be better (Nunnally \& Bernstein, 1994). Abdel-Khalek (2006) demonstrates that measuring happiness using the single-item scale 'Do you feel happy in general?' can have good temporal stability and concurrent, convergent, and divergent validity. Other studies show that single-item measures on different topics can have good psychometric properties (Bergkvist \& Rossiter, 2007). A researcher who would like to use a multi-item scale to measure happiness defined as liking the life one leads might use the Satisfaction With Life Scale (Diener et al., 1985). This scale was designed to measure life satisfaction.

A systematic overview of all the variations in survey items on happiness can be found in the collection 'Measures of Happiness' of the World Database of Happiness (WDH).

If a researcher prefers to define happiness as subjective well-being (SWB), they have to use at least three scales because SWB consists of at least three dimensions: life satisfaction, positive affects and negative affects. As mentioned above, life satisfaction can be measured using the Satisfaction With Life Scale (Diener et al., 1985). Positive and negative affects can be measured using a scale like the Positive Affect and Negative Affect Schedule (PANAS; Watson et al., 1988). If a researcher prefers to use Kahneman's objective happiness model, they can use the Day Reconstruction Method (DRM; Kahneman et al., 2004). If a researcher prefers to define happiness as an eudaimonic phenomenon, they can use the scale developed by Ryff and Keyes (1995) that fits Ryff's model of psychological well-being (PWB).

Using the short version of Veenhoven's definition of happiness is an advantage when it comes to measuring happiness, because it is possible to use a single-item measure and there is just one dimension to measure. This is not the case when using SWB and PWB models. When using the SWB model, three dimensions have to be measured, which means three times more calculations if this model is used in further calculations. When using the PWB model, six dimensions have to be measured. Kahneman et al.'s (2004) measure of objective happiness is too complicated to be used on a long period because completion times ranges from 45 to $75 \mathrm{~min}$ to evaluate objective happiness for just one day.

\section{Lifetime and Happiness}

Happiness may have an objective aspect, the duration of a person's life. Veenhoven (1996) developed the Happy life-expectancy index to assess how much of a person's life the life is happy and for how long in different countries. Veenhoven does not use duration of a life because this is only known once someone has died and he wants a measure that can be used to assess the current situation. Veenhoven's index is measured at the country level, however, it could be adapted to the individual level. It is easy to obtain a measure of happiness and it is possible to evaluate life expectancy 
more accurately at the individual level. Life expectancy may be influenced by gender, occupational status, health history, habits, etc.

Kahneman (1999) defines happiness as the average balance of emotions over a period of time. Imagine two people who have the same, stable degree of emotions over all their lives. This hypothesis is unrealistic, but it allows us to understand the importance of lifetime in happiness. Imagine now that the only difference between these two people is that the first lives for 40 years and the second for 80 years. If we think of happiness as an integral, then the second person lives twice as much happiness as the first one. Length of the lifetime matters in happiness. If living 80 years rather than 40 years is a way to be happier, then living 160 years rather 80 years is a way to be happier, and the search for immortality is also so. Some researchers and firms are working on ways to lengthen significantly the duration of human life. The future being uncertain, we cannot know to what extent they will succeed, but we can look back in history and see that three hundred years ago, in France, we needed two children to make one adult (Goubert, 1968). This meant that only one in two children lived long enough to reproduce. In three hundred years, conditions have changed. Today, in rich countries, people live on average more than seventy years.

If scientists do manage to lengthen the duration of the human life, some new issues will occur. We will need to reduce the human population and find ways to use the limited resources of the Earth efficiently. If we find ways to live much, much longer, it will not be three or four generations living, but five, six, seven... This will generate a new demographic transition.

\section{Happiness Policies}

\section{Public Budgeting, Public Spending and Classical Public Policies}

Key (1940) asks the budgeting question: 'On what basis shall it be decided to allocate X dollars to activity A instead of activity B?'.

Public policies are implemented in numerous domains: health, education, housing, agriculture, energy, economics, justice, police, army, land-use planning, to name but a few, and these policies are implemented by a lot of authorities: local, regional, national, supranational authorities.

In public policies, allocations are made using a budget. A budget links the activities to be performed and the financial resources required to perform these activities (Rubin, 2019). Three budget formats exist: the line item budget, program budget and performance budget. A line item budget allocates funds to objects of cost. The major shortcoming of a line item budget lies in its inability to describe the activity performed. A program budget allocates funds to programs. They allow authorities to plan for more than a fiscal year. In a good program budget goals are listed with the funds allocated to reach them. A performance budget is characterized by a classification of funds per activity and the direct expected output that an activity should generate. An advantage of a performance budget is to bring accountability, however, it is not always possible to relate cause to effect. Some budgeting techniques may be applied to each budget format, for example incrementation or zero-based budgeting. 
In an incremental approach, funds are added or subtracted from the previous budget. In zero-based budgeting, each budget has to be justified from beginning to end (Menifield, 2017).

Rubin (2019) considers that a public budget reflects choices about what an authority will and will not do, priorities, the degree of importance that an authority places on satisfying inhabitants and responding to interest group demands, and citizens' preferences for different forms and level of taxation. Rubin also considers that a budget provides a picture of the relative power of budget actors. Since Samuelson (1938), economists have used the concept of revealed preference to describe that what a consumer spends money on is the best indicator of what a consumer really wants. Authorities, like consumers, reveal what is important for them through the services and products they buy and do not buy.

Ortiz-Ospina and Roser (2020) analyse government spending. They find that government spending in early-industrialized countries grew remarkably during the last century, and that this growth was largely driven by social spending. They also find that governments in high-income countries, particularly those in Europe, control a larger share of national production than governments in low-income countries, and that high-income countries spend more on social protection than low-income countries proportionally. Governments also differ in priorities. Finally, government spending is an important instrument to use when seeking to reduce inequality. Countries that manage to achieve the largest redistribution of wealth using taxes and transfers tend to be those with the lowest after-tax inequality.

Pradhan (1996) states that the composition of public expenditures should finance the mix of goods and services that governments need to provide to maximize social welfare, and Pradhan gives three criteria for analysing expenditure allocation: the role of the public versus the private sector, the social cost-benefit of expenditures and outcomes, the impact on the poor. I can say that happiness could be another criterion, or, maybe, because happiness is an ultimate goal, the only criterion to use.

\section{Public Policies as Determinants of Happiness}

Lyubomirsky et al. (2005) distinguish three kinds of determinants of happiness: a genetically determined set point for happiness, happiness-relevant circumstantial factors, and happiness-relevant activities and practices. The set point is genetically determined, it is fixed and stable over time and cannot be influenced or controlled. It is possible that researchers will be able to alter this set point in the future, however: Would this be a good idea? Happiness-relevant circumstances include an individual's personal history, and sociodemographic characteristics such as gender, age, ethnicity, marital status, occupational status, job security, income, financial security, wealth, health, values, culture and religious affiliation. Happiness-relevant activities and practices are called intentional activity by Lyubomirsky et al. (2005), and these include everything people think and do, for example trying to be kind to others, a behavioural activity, reframing situations in a more positive light, a cognitive activity, and striving for important personal goals, a volitional activity. The main difference between circumstances and intentional activity is that circumstances happen 
to people, whereas intentional activity is how people choose to influence these circumstances.

Although Lyubomirsky et al. (2005) do not add the duration of a lifetime into their definition of happiness, their categorization of the determinants of happiness is also relevant for categorizing the determinants of the duration of a lifetime. The duration of an individual's lifetime is influenced by genetics, for example certain illnesses are more common in some ethnic groups; life circumstances, for example a good quality accessible health system in the country where we are born will help us live longer; and intentional activities, for example having a healthy diet can reduce the likelihood acquiring some illnesses.

If Lyubomirsky et al.'s typology of determinants of happiness are relevant for public policies, it would be useful to include this typology into another typology, one that distinguishes between two kinds of determinants of our own happiness: individual and collective determinants. Individual determinants are everything we can do for ourselves efficiently to help us to be happy or happier, collective determinants are everything the society does for us efficiently to be happy or happier. Public policies as determinants of happiness are categorized as collective determinants.

Public policies can be determinants of happiness when their goal is to create a better environment for happiness to thrive, including the objective aspect of happiness, life duration, and when they allow policy makers to reach this goal. We can call these policies happiness policies.

Public policies can act as potential determinants of happiness for the three kinds of determinants of happiness that Lyubomirsky et al. defined (2005). It is possible to finance research on how to alter a set point in the future, even if doing so might not be recommended. It is also possible to finance public policies that aim to build better circumstances, for example that are aimed at avoiding war, at providing physical and psychological security, or at providing people with more control over their own lives thanks to better organized societies. It is possible to finance public policies that help people develop happiness-relevant activities and practices, for example by implementing education programs that help young people to build psychological resources they can use to build a happier life, or facilitating access to psychological health professionals for people who need help, and even for people who just want to develop the positive dimension of their psychological health further. Public policies can also be used to reduce premature deaths. Public policies can be set up to finance research into premature deaths and ways to avoid them, and then these policies can be put into practice.

Research on the effects of government spending decisions on the happiness of people has grown since the early 2000s. Part of this research is about the size of the government and studies may differ in their conclusions. Some studies show that happiness increases with public spending, see Flavin et al. (2014) and Perovic and Golem (2010), while other studies find no relationship or even the opposite, see Veenhoven (2000) and Bjørnskov et al. (2007).

There is also growing research on the influence of various kinds of public spending on the happiness of people. For example, Leyden et al. (2011) find, having studied 10 urban areas, that cities that provide easy access to public transportation and to cultural and leisure amenities promote happiness as do cities that are affordable and 
a good place to raise children. Sjöberg (2010) show that the 'generosity of unemployment benefits makes a difference to the subjective well-being of employed individuals, especially those with limited economic resources and an insecure position in the labor market'.

If good governance matters in traditional public spending, it also matters when it comes to happiness. Ott (2011) asks what the relationship between the quality of government and two outcomes, average happiness in nations and inequality in happiness in nations, is. Ott shows that good governance fosters a higher degree of happiness and lowers inequality of happiness.

\section{Ethical Framework for Policymakers and Happiness Policies}

Is an authority, one that wants to make its citizens and inhabitants happy or happier, always a good authority? No. I can give at least two reasons in support of this statement. One: there are historical examples of authorities that have acted badly against people they wanted to make happy. Two: happiness can be a tyranny (Bruckner, 2002).

Using a scientific, quantitative approach in public policies is a way to avoid authorities acting badly because the results of happiness policies should be measured, however, measuring happiness is not enough. This is why I propose an ethical framework to use when developing happiness policies.

1. Happiness is private and personal.

2. Everyone has the right to be unhappy and his or her unhappiness should be respected

3. The goal of happiness policies is not to make individuals happy or happier, but to build a more favourable environment for them to build their own happy or happier lives.

4. Happiness policies cannot be developed against the will of the people for whom they are intended.

Thus, the optimization is not between public spending and happiness, but between public spending and social conditions for happiness.

\section{Optimization}

\section{Defining Optimization}

Bentham (1776/2001) states that a 'fundamental axiom [...] is the greatest happiness of the greatest number that is the measure of right and wrong'. This is the greatest happiness principle and the basis of utilitarian philosophy. Conversely, Popper (1952) states that 'human suffering makes a direct moral appeal for help, while there is no similar call to increase the happiness of a man who is doing well anyway'. This approach is called negative utilitarianism. According to what is considered the best 
Table 1 The utilitarianist costhappiness matrix for public policies

\begin{tabular}{lll}
\hline & $\begin{array}{l}\text { Low positive influence on } \\
\text { happiness }\end{array}$ & $\begin{array}{l}\text { High positive } \\
\text { influence on hap- } \\
\text { piness }\end{array}$ \\
\hline Low cost & \pm & + \\
High cost & - & \pm \\
\hline
\end{tabular}

Key:

$+:$ what we want to find

\pm : neutral

-: what it may be useful to avoid

approach, utilitarianism or negative utilitarianism, what I mean when using the term optimization is different.

In utilitarianism, optimization can be defined as achieving the highest influence of happiness with the lowest need for financial resources, see Table 1 in which lowcost public policies having high positive influence on happiness is what is sought.

There can be different kinds of utilitarianist optimization between public spending and social conditions for happiness:

a. improving social conditions for happiness while keeping the same degree of public spending

b. reducing public spending while keeping the same degree of quality of social conditions for happiness

c. improving social conditions for happiness, but less than in option (a), and decreasing public spending, but less than in option (b)

In negative utilitarianism, optimization can be defined as achieving the highest positive influence on the happiness of the least happy/ the saddest with the lowest need for financial resources, see Table 2 in which low-cost public policies having high positive influence on the happiness of the least happy/ the saddest is what is sought.

There can be different kinds of negative utilitarianist optimization between public spending and social conditions for happiness:

Table 2 The negative utilitarianist cost-happiness matrix for public policies

Low influence on the happiness of the least High positive influence on the happy/ the saddest happiness of the least happy/ the saddest

\begin{tabular}{lll}
\hline Low cost & \pm & + \\
High cost & - & \pm \\
\hline
\end{tabular}

Key:

+ : what we want to find

\pm : neutral

-: what it may be useful to avoid 
a. improving social conditions for happiness of the least happy/ the saddest while keeping the same degree of public spending

b. reducing public spending while keeping the same quality of social conditions for happiness of the least happy/ the saddest

c. improving social conditions for happiness of the least happy/the saddest, but less than in option (a), and decreasing public spending, but less than in option (b).

As I value negative utilitarianism more, I consider that it is always best to begin with a negative utilitarianist approach rather than with a utilitarianist approach and I propose the following process. First, identify the less happy people, understand how public policies can create a more favourable environment for them and implement such policies; then, understand how public policies can create a favourable environment for the greatest happiness for the greatest number, and implement such policies; finally, understand if specific public policies can explain the degree of happiness of the happiest people, and, if they do, understand how they do and implement such policies.

\section{The Bookkeeping Approach and the Econometric Approach}

There is a simple tool to optimize the relationship between public spending and social conditions for happiness. The idea is to design a public policy or part of it to improve social conditions for happiness, whether in a utilitarianist approach or, as I prefer, in a negative utilitarianist approach. This design can be made by doing a literature review, and using the World Database of Happiness can help, or by doing a Delphi study, see as an example Buettner et al. (2020). We then have to assess the cost of the new policy and compare this cost to the cost of the current policy. The assessment can be made using line item budget, a program budget or a performance budget. Finally, we have to decide if we change the policy or not. This tool falls within a bookkeeping approach. If the happiness policy is implemented, we will have to determine if the expected results have been reached.

The econometric approach is more complex and needs more explanation. In the following subsections, I will present the useful data to collect for the econometric approach, explain why quantile regression is the best tool in a negative utilitarianist and econometric approach, and provide an econometric model to help optimize the relationship between public spending and social conditions for happiness.

\section{Useful Variables in the Econometric Approach}

At least seven kinds of variables can be used to optimize the relationship between public spending and social conditions for happiness when an econometric approach is taken. We will explain how these variables can be used to optimize the relationship between happiness and social conditions for happiness in subsection 4.5.

Measure(s) of Happiness How happiness is measured depends on how happiness is defined. In my opinion, the best definition of happiness is how much one likes the 
life one leads and a relevant measure is the single-item scale 'How much do you like the life you lead?', however, other definitions and measures of happiness exist and can be used. The more dimensions a definition of happiness has, the more dimensions the subsequent measure of happiness has, and the more calculations will have to be done when trying to optimize the relationship between public spending and social conditions for happiness.

Measures of Sociodemographic Features These measures are traditionally gathered in a scientific study. Here I propose a list of such measures, however, this list is not comprehensive and should be adapted and extended to the specific research field: gender, age, education, culture, native language, race, income, wealth, marital status, occupational status, health condition, homeownership status, neighbourhood, i.e. urban or rural, district, etc. Such measures allow us to:

- know if some categories of people are least happy/sadder than others

- control the representativeness of a study regarding each feature, selection bias being often a major limitation of studies

- study a specific population, for example the homeless or the unemployed.

Objective Measures of Collective Determinants of Happiness An objective measure is a measure that is not drawn from the perceptions of a human being, for example measured electricity consumption or the number of medical doctors per 1,000 inhabitants in an area. Any objective measure can be used statistically if it fulfils two conditions. One: data have been collected at the individual level or at a group level. Two: there are at least some thirty individuals or groups. If data fulfil these two conditions, then we can use it in econometric models.

Subjective Measures of Collective Determinants of Happiness Subjective measures can be much easier to use than objective measures, because they are collected at the same level as measures of happiness, the level of the individual. Two examples of these measures can be 'How satisfied are you with the public transportation system in your city?' and 'How satisfied are you with the public transportation policy of the city?'.

A subjective measure is a measure that results from the perceptions of a human being. As perceptions can be false or imprecise, some people may think that objective measures are better than subjective measures, however, perceptions have a value, whether they are a good assessment of reality or not, because these perceptions may influence the degree of happiness of an individual and may be exposed behaviourally. Observed perceptions can sometimes be an indication that an objective measure is biased.

At least two kinds of subjective data on collective determinants of happiness are interesting for us to collect: one, data on an individual's feelings on the current quality of different domains, that is how people feel about a current situation, and two, data on an individual's feelings about current policies for these different domains, how people feel about the direction of the efforts to modify a situation or the fact that a current situation is seen to be unchanged. We use the word 'feelings' and the 
associated verb rather than the word 'perception' to show that both domain satisfaction measures and affect measures exist and can be assessed. Subjective appraisal may be cognitive, affective or both. All domains of public policies can become a topic for subjective assessment and each domain can be investigated in-depth.

Financial Measures We can use two kinds of financial data to optimize the relationship between public spending and social conditions for happiness: a detailed budget and different index.

A detailed budget is useful to understand which budget item should receive more finance, less or to stay stable, given the results of some form of measurement of happiness. The detailed budget can be a line item budget, a program budget or a performance budget. If the authority is divided into more than thirty districts and financial data are available for each district, it is possible to optimize the relationship between public spending and social conditions for happiness study using econometric tools. If authorities want to help each other to optimize the relationship between public spending and social conditions for happiness, there need to be more than thirty members in the group for the econometric tools to be used effectively.

There is a field of research on finance in which researchers create new measures with existing data and use these measures to understand better finance. It is possible to create an index of what an authority has spent for each inhabitant, not the average public spending per inhabitant because such a measure does not allow us to discriminate inhabitants, but an estimate of the amount of money spent per inhabitant individually. Practically, it can be done as follows. If it is not possible to discriminate expenditure per inhabitant, we can use an average. If it is possible, then we discriminate per inhabitant. For example, take education, we consider that no public money is spent for people without children and public money is spent on people with children. The amount of money spent can vary depending on the age of a child and the services or the lack of services provided by the authority. Such a general index is constructed, by definition, using multiple policy-specific indexes that can also be used independently. As creating and using financial indexes is a new field, any results stemming from this approach must be considered cautiously. For example, a district with the highest degree of violence could be among the districts where inhabitants are the unhappiest and where spending more public money may help to solve the issues. The use of an index as I have described can lead to awkward results if they are not used properly.

Control Variables A control variable is a variable that may affect the dependent variable in a regression, it is used to take into account its effect on a dependant variable so that we can ignore it and just study the relationships between the independent variables and the dependent variable. According to a situation, some of the variables I have presented can be used as control variables. For example, income and wealth may have been used as control variables in a previous example on happiness, violence, and public spending. Measures of personality traits can be useful control variables. Some traits are positively linked with happiness, while other traits are negatively associated with it, however, it may be complicated, or even unethical or 
illegal, for an authority to ask inhabitants to answer questions regarding their personality traits.

Measures for Special Topics If a follow-up study is conducted on a specific topic, specific measures may be useful. For example, if the studied population is victims during and after legal proceedings, data may need to be collected more frequently to arrive at a better understanding on how the affects of being a victim evolve. Specific measures can be used to get information about specific domains such as police behaviour, judges' behaviour, ease of understanding legal proceedings, quality of victim support, etc.

\section{Negative Utilitarianism and Quantile Regression}

While utilitarianism emphasizes the greater happiness of the greater number, negative utilitarianism focused on the least happy/the saddest people, however, it is difficult to define precisely who they are, because a threshold has to be defined. This threshold may be a percentage of the whole population, a degree of declared happiness, or a deviation from the average or the median.

Unlike classical regressions that model the way the conditional means vary depending on independent variables, quantile regression allows us to determine how each quantile varies depending on independent variables. The quantile regression has at least three advantages. One: quantile regression facilitates negative utilitarianist optimization, because it makes possible to know which independent variables influence most the degrees of appreciation of life of the least happy/ the saddest. Note that quantile regression also makes it possible to determine the influence of an independent variable for the median people and the happiest.

Two: implementing a public policy for the least happy/the saddest does not mean that this policy has no impact on the rest of that population. Given the variations in the impact of independent variables, quantile regression allows us to grasp how the impact of independent variables varies according to the degree of happiness of participants. It is possible to see the consequences of the most important variables for the least happy/ the saddest people for other people in their population, whether these variables help to build public policies or are about public policies.

Three: using quantile regression makes the precise definition of a threshold between the least happy/the saddest and the other less important. That either we define the least happy/the saddest of a population as the $\mathrm{x} \%$ less happy or the people who declare to be under y on a 1 to 10 scale, or as the influence of a public policy for the least happy/the saddest will also have an influence on the rest of the population, the threshold we define can be voluntarily fuzzy.

\section{An Econometric Model}

We will now propose a simple model that can be used to optimize the relationship between public spending and social conditions for happiness. 
This econometric model can be developed using classical OLS regression when it falls within an utilitarianist approach, however, as I prefer a negative utilitarianist approach, I think it is better to use quantile regression.

From a statistical point of view, optimization needs causality and variance. A causal relationship allows us to make predictions about the consequence of a change. 'It will tell us what could happen in an alternative world' (Angrist \& Pischke, 2009). In a situation in which it is difficult to prove causality, it is possible to use correlational findings on one condition: one must be aware of their limitations. The best way to collect data when it is not possible to conduct an experiment is to have a time lag between the time when data on independent variables are collected and the time when data on dependent variables are collected. Not all independent variables need this, for example age, happiness cannot change the number of years a person have been alive, but most of the independent variable need this treatment.

Variance is useful because we cannot measure the influence of one phenomenon over another if neither of the two phenomena change overtime. It is even possible to create variance rather than just using existing variance: every implementation of a new public policy may create variance and this variance can be used to extract more intelligence from the data. The most interesting kinds of variance are intra-individual and inter-individual variance, because happiness is measured at an individual level, but using intra-individual variance needs more than one data collection and using intra-individual and inter-individual variances are only possible if the other data used are also collected or assessed at an individual level. This is not usually the case for financial measures and objective measures of collective determinants of happiness. It is also possible to want to compare data at another level than the individual level, for example cities, regions or states that might want to work together to implement happiness policies. As my aim with this paper is to help any authority to optimize the relationship between public spending and social conditions for happiness, I have focused this paper on what an authority can do by itself, however, it is possible for authorities to cooperate, collect the same kinds of data and use interauthority variance to get more variance and more intelligence from a wider set of data.

We can optimize the relationship between public spending and social conditions for happiness directly. The measure of happiness used in the econometric model should be collected at time $t$ and financial measures collected at time $t-n(n \geq 1)$. In doing this, we cannot be sure there is a causal link from public spending to happiness, however, we will at least obtain a longitudinal correlation.

What is the influence of different kinds of public spending on happiness according to numbers? The econometric solution is:

$$
\text { happiness }_{\mathrm{i}}=\text { financial measures }_{\mathrm{i}} \cdot \beta_{\mathrm{i}}+\varepsilon_{\mathrm{i}}
$$

where financial measures represent a vector of many specific budgets.

This equation is basic and it is possible to have a more elaborated econometric model. For example, when a financial measure is used, this variable often receives a logarithmic transformation. It can also be relevant to use control variable. Using this equation allows us to distinguish what the impact of each specific budget on 
happiness is. If we use quantile regression, it allows us to see how each specific budget may have a different impact on the degree of happiness of each quantile of inhabitants. Thus, it becomes possible to know if it would be a good idea to increase, reduce or stabilize a specific budget. The decision making still belongs to decision makers, however, the decision makers can make better informed decisions.

We can also optimize the relationship between public spending and social conditions for happiness indirectly. The word indirectly here is used to mean that we use measures that are not financial but that allow an authority to choose better its public policies so that these policies will have a higher impact on happiness and, or a lower cost. There are at least three ways to realize this objective, one is to use sociodemographic features:

$$
\text { happiness }_{\mathrm{i}}=\text { sociodemographic features }_{\mathrm{i}} \cdot \beta_{\mathrm{i}}+\varepsilon_{\mathrm{i}}
$$

where the sociodemographic features are a vector of the sociodemographic features. The measure of happiness should be collected at time $t$ and the measures of objective variables of collective determinants of happiness should be collected at time $\mathrm{t}-\mathrm{n}(\mathrm{n} \geq 1)$.

Studying the relationship between sociodemographic features and happiness allow us to know the average degree of happiness of each group within a population so that it is possible to develop specific public policies to target the unhappiest groups. People with a low degree of happiness can be found in groups with a high degree of happiness and people with a high degree of happiness can be found in groups with a low degree of happiness, however, studying the relationship between sociodemographic features will allow authorities to take more relevant action by targeting specific sociodemographic groups. The consequence will be a better allocation of financial resources when it comes to using financial resources to influence social conditions for happiness in a negative utilitarianist way. Policy makers can target the unhappiest groups more and the happiest groups less. Financial optimization is not precise, but the allocation of financial resources will be better. Note: it is possible that targeting less the happiest group may lead to political issues.

Two: is to optimize the relationship between public spending and social conditions for happiness indirectly using objective measures of collective determinants of happiness:

$$
\text { happiness }_{\mathrm{i}}=\text { objective variables of collective determinants of happiness }_{\mathrm{i}} \cdot \beta_{\mathrm{i}}+\varepsilon_{\mathrm{i}}
$$

where the objective variables of collective determinants are a vector of objective variables of collective determinants. The measure of happiness should be collected at time $t$ and the measures of objective variables of collective determinants of happiness should be collected at time $t-n(n \geq 1)$.

An authority can use the result of this equation to understand if a public policy needs to be implemented, reinforced or abandoned. Imagine a determinant that is the result of a public policy or that can be influenced by implementing a public policy. If this determinant has a positive influence on happiness of the least happy/ the sadder, then the public policy can be reinforced. If this determinant has no influence, then the public policy can be reduced or even suppressed. If the determinant has a 
positive influence on the happiness of the happiest or if it has a negative influence on happiness, then it is possible to reduce or suppressed the associated public policy. It is these ways that the equation can be used to optimize the relationship between public spending and social conditions for happiness.

Three: is to optimize the relationship between public spending and social conditions for happiness indirectly using subjective measures of collective determinants of happiness:

$$
\text { happiness }_{\mathrm{i}}=\text { subjective variables of collective determinants of happiness }_{\mathrm{i}} \cdot \beta_{\mathrm{i}}+\varepsilon_{\mathrm{i}}
$$

where the subjective variables of collective determinants are a vector of subjective variables of collective determinants. The measure of happiness should be collected at time $t$ and the measures of subjective variable of collective determinants of happiness should be collected at time $t-n(n \geq 1)$.

There is one difference between how the results obtained using subjective measures of collective determinants of happiness should be used and how the results obtained using objective measures of collective determinants of happiness should be used. It is more difficult to analyse results obtained using subjective measures, because it can be unclear, if a result shows a relationship between a subjective measure of a collective determinant of happiness and social conditions for happiness, whether a policy should be implemented or reinforced, or whether the perceptions of inhabitants should be modified, or both. This is why it is important to use objective measures when deciding happiness policies whenever possible.

After happiness policies based on negative utilitarianist optimization have been implemented successfully, it is possible to use updated data and quantile regression for utilitarianist optimization and implementation of happiness policies for the greater happiness of the greater number. After happiness policies based on utilitarianist optimization have been implemented successfully, it is possible to use updated data and quantile regression for optimization and implementation of happiness policies by learning from the happiest. It is possible to use the same method to know more about a specific domain and optimize the relationship between public spending and social conditions for happiness in that domain; we just need specific data for specific, in-depth study.

\section{Limitations}

There are at least four limitations to the two methods useful for optimizing the relationship between public spending and social condition for happiness, i.e. the bookkeeping method and the econometric method. One: self-selection bias. There are two kinds of people: those will participate in a study and respond to questions and those who will not. We cannot deal with this difference and this difference may hide other problems. If we have data on a whole population, it is possible to control if our sample is representative for the features we can control.

Two: people have a tendency to present themselves in the most favourable manner they can relative to prevailing social norms in human interactions. This tendency is called social desirability bias. A feeling of anonymity when answering a 
questionnaire reduces and even makes this tendency disappear. It is possible that for some populations such as the homeless or seniors that human interaction will be necessary to collect data rather than relying on anonymous collection via the Internet, this will reduce their feeling of anonymity and increase social desirability bias.

Three: people need freedom and confidence to respond directly, stating what they feel. This means that they need to know that their responses will not be overseen and cannot be used against them. The higher the degree of feeling of freedom in a country, the higher the likelihood people will respond freely saying what they think.

Four: people can behave strategically. If happiness becomes increasingly important with respect to building public policies, certain people may respond according to effects they want to provoke rather than with answers that reflect what they truly feel. Researchers in psychology use various methods to avoid such behaviours and to control for them, such as the way they structure a questionnaire and how they pay statistical attention to extreme values.

\section{Reducing Premature Deaths}

We have seen that policies aimed at reducing early deaths tend to be happiness policies. The more premature a death is, the more important it is that public policies should be implemented aimed at avoiding such deaths.

There are two situations. Either we have a record of the cause of every premature death, and we can use it, or we do not, then we have to generate a record. Such a record will allow authorities to build relevant happiness policies and prioritize public spending. The prioritization may be done using two indicators: the prematurity of a death and its cause. The more premature deaths a cause makes, the more important the prevention of this cause will become.

As the causes of premature deaths can change from one authority to another, public policies will also need to change their approaches. An authority can adapt its public policies to its specific record, however, this is not possible for authorities with small populations, because the results may not be representative of a particular population.

Implementing a public policy for a specific cause of premature death may be difficult and choices must be made. For example, to reduce the childhood cancer rate, research, medicine, and a better environment might be simultaneously necessary and fostering a better environment for children is not just about money, it is also about producing differently. Finding trade-offs between conditions required to reduce premature deaths will allow authorities to spend more effectively.

\section{Conclusion}

My aim with this paper was to bring to local, regional, national and supranational authorities a set of simple methods for optimizing the relationship between public spending and social conditions for happiness. I consider that people in our world could be much happier than they are and that public policies based on the advancements being made in the science of happiness are a leading means to fulfil this goal. 
In this paper, we saw that how much one likes the life one leads may be the best definition of happiness; that a single-item scale allows us to measure happiness defined in this way. That the duration of life counts in happiness. That it is possible to develop public policies that foster the social conditions for happiness. That an ethical framework allows us to delimitate what happiness policies are so that happiness does not become a tyranny. That it is possible to optimize the relationship between public spending and social conditions for happiness in an utilitarianist way and in a negative utilitarianist way. That negative utilitarianism may be a better choice, because the suffering of human beings makes a direct moral appeal for help. That it is possible to optimize the relationship between public spending and social conditions for happiness using a bookkeeping method and an econometric method. That the econometric method may need or requires some variables such as a measure of happiness, measures of sociodemographic features, objective and subjective measures of collective determinants of happiness, and financial measures. That the econometric method requires we use quantile regression in the negative utilitarianist perspective. That it is possible to have some insights to optimize the relationship between public spending and happiness using some basic equations. That the two methods discussed here have the limitations of subjective data, because happiness is mainly a subjective phenomenon. Finally, that optimizing the relationship between public spending and the objective dimension of happiness, duration of life, is also complicated.

Future research on how to optimize the relationship between public spending and social conditions for happiness is needed, because the methods, as presented above, are basic and needs to be developed further. In a world already suffering from ecological damages and threatened by more, it may also be possible to develop the methods further to optimize the relationship between consumption of natural resources and happiness. In this perspective, financial resources would be replaced by natural resources, and my methods could be adapted to accommodate this change.

\section{Declarations}

Conflict of Interest The authors declare that they have no conflicts of interest.

Open Access This article is licensed under a Creative Commons Attribution 4.0 International License, which permits use, sharing, adaptation, distribution and reproduction in any medium or format, as long as you give appropriate credit to the original author(s) and the source, provide a link to the Creative Commons licence, and indicate if changes were made. The images or other third party material in this article are included in the article's Creative Commons licence, unless indicated otherwise in a credit line to the material. If material is not included in the article's Creative Commons licence and your intended use is not permitted by statutory regulation or exceeds the permitted use, you will need to obtain permission directly from the copyright holder. To view a copy of this licence, visit http://creativecommons.org/licen ses/by/4.0/. 


\section{References}

Abdel-Khalek, A. M. (2006). Measuring happiness with a single-item scale. Social Behavior and Personality: An International Journal, 34(2), 139-150.

Adler, M. D., Dolan, P., \& Kavetsos, G. (2017). Would you choose to be happy? Tradeoffs between happiness and the other dimensions of life in a large population survey. Journal of Economic Behavior \& Organization, 139, 60-73.

Aknin, L. B., Van de Vondervoort, J. W., \& Hamlin, J. K. (2018). Positive feelings reward and promote prosocial behavior. Current Opinion in Psychology, 20, 55-59.

Angrist, J. D., \& Pischke, J. S. (2009). Mostly harmless econometrics: An empiricist companion. Princeton University Press.

Bentham, J. (1948) An introduction to the principles of morals and legislation. Blackwell (Originally published in 1789).

Bentham, J. (2001). A fragment on government. The Lawbook Exchange (Originally published in 1776).

Bergkvist, L., \& Rossiter, J. R. (2007). The predictive validity of multiple-item versus single-item measures of the same constructs. Journal of Marketing Research, 44(2), 175-184.

Bjørnskov, C., Dreher, A., \& Fischer, J. A. (2007). The bigger the better? Evidence of the effect of government size on life satisfaction around the world. Public Choice, 130(3-4), 267-292.

Bruckner, P. (2002). L'euphorie perpétuelle: Essai sur le devoir de bonheur. Livre de Poche.

Buettner, D., Nelson, T., \& Veenhoven, R. (2020). Ways to greater happiness: A Delphi study. Journal of Happiness Studies, 21(8), 2789-2806.

Diener, E. (1984). Subjective well-being. Psychological Bulletin, 95(3), 542-575.

Diener, E., Napa-Scollon, C. K., Oishi, S., Dzokoto, V., \& Suh, E. M. (2000). Positivity and the construction of life satisfaction judgments: Global happiness is not the sum of its parts. Journal of Happiness Studies, 1(2), 159-176.

Diener, E., Suh, E. M., Lucas, R. E., \& Smith, H. L. (1999). Subjective well-being: Three decades of progress. Psychological bulletin, 125(2), 276-302.

Diener, E. D., Emmons, R. A., Larsen, R. J., \& Griffin, S. (1985). The satisfaction with life scale. Journal of Personality Assessment, 49(1), 71-75.

Flavin, P., Pacek, A. C., \& Radcliff, B. (2014). Assessing the impact of the size and scope of government on human well-being. Social Forces, 92(4), 1241-1258.

Goubert, P. (1968). Cent mille provinciaux au XVIIe siècle : Beauvais et le Beauvaisis de 1600 à 1730. Flammarion.

Haybron, D. M. (2008). Philosophy and the science of subjective well-being. In M. Eid, \& R. J. Larsen (Eds.), The science of subjective well-being (pp. 17-43). Guilford Press.

Hickel, J., \& Kallis, G. (2020). Is green growth possible? New Political Economy, 25(4), 469-486.

Kahneman, D., Krueger, A. B., Schkade, D. A., Schwarz, N., \& Stone, A. A. (2004). A survey method for characterizing daily life experience: The day reconstruction method. Science, 306(5702), 1776-1780.

Kahneman, D., Wakker, P. P., \& Sarin, R. (1997). Back to Bentham? Explorations of experienced utility. The Quarterly Journal of Economics, 112(2), 375-406.

Kainulainen, S., Saari, J., \& Veenhoven, R. (2018). Life-satisfaction is more a matter of feeling well than having what you want. Tests of Veenhoven's theory. International Journal of Happiness and Development, 4(3), 209-235.

Kahneman, D. (1999). Objective happiness. In D Kahneman, E. Diener, \&, N. Schwarz (Eds.), Wellbeing: The foundations of hedonic psychology (pp. 3 -25). Russell Sage Foundation.

Key, V. O. (1940). The lack of a budgetary theory. American Political Science Review, 34, 1137-1144.

Kirchler, E. (2007). The economic psychology of tax behaviour. Cambridge University Press.

Leyden, K. M., Goldberg, A., \& Michelbach, P. (2011). Understanding the pursuit of happiness in ten major cities. Urban Affairs Review, 47(6), 861-888.

Lyubomirsky, S., King, L., \& Diener, E. (2005). The benefits of frequent positive affect: Does happiness lead to success? Psychological Bulletin, 131(6), 803-855.

McMahon, D. M. (2006). Happiness: A history. Grove Press.

Menifield, C. E. (2017). The basics of public budgeting and financial management: A handbook for academics and practitioners. Hamilton Books.

Nunnally, J. C., \& Bernstein, I. H. (1994). Psychometric theory. McGraw-Hill. 
Ott, J. C. (2011). Government and happiness in 130 nations: Good governance fosters higher level and more equality of happiness. Social Indicators Research, 102(1), 3-22.

Ortiz-Ospina, E., \& Roser, M. (2020). Government spending. Published online at OurWorldInData.org. Retrieved from: https://ourworldindata.org/government-spending. Accessed 2020

Perovic, L. M., \& Golem, S. (2010). Investigating macroeconomic determinants of happiness in transition countries: How important is government expenditure? Eastern European Economics, 48(4), 59-75.

Popper, K. R. (1952). The open society and its enemies. Routledge \& Kegan Paul.

Post, S. G. (2005). Altruism, happiness, and health: It's good to be good. International Journal of Behavioral Medicine, 12(2), 66-77.

Pradhan, S. (1996). Evaluating public spending: A framework for public expenditure reviews. The World Bank.

Rubin, I. S. (2019). The politics of public budgeting: Getting and spending, borrowing and balancing. CQ Press.

Ryff, C. D. (1989). Happiness is everything, or is it? Explorations on the meaning of psychological wellbeing. Journal of Personality and Social Psychology, 57(6), 1069-1081.

Ryff, C. D., \& Keyes, C. L. M. (1995). The structure of psychological well-being revisited. Journal of Personality and Social Psychology, 69(4), 719-727.

Samuelson, P. A. (1938). A note on the pure theory of consumers behaviour. Economica, 5, 61-71.

Sjöberg, O. (2010). Social insurance as a collective resource: Unemployment benefits, job insecurity and subjective well-being in a comparative perspective. Social Forces, 88(3), 1281-1304.

Veenhoven, R. (1984). Conditions of happiness. D. Reidel.

Veenhoven, R. (1996). Happy life expectancy. Social Indicators Research, 39(1), 1-58.

Veenhoven, R. (2000). Well-being in the welfare state: Level not higher, distribution not more equitable. Journal of Comparative Policy Analysis: Research and Practice, 2(1), 91-125.

Veenhoven, R. (2010). How universal is happiness? In E. Diener, J. F. Helliwell, \& D. Kahneman (Eds.), International differences in well-being (pp. 328-350). Oxford University Press.

Veenhoven, R., \& Hagerty, M. (2006). Rising happiness in nations 1946-2004: A reply to Easterlin. Social Indicators Research, 79(3), 421-436.

Watson, D., Clark, L. A., \& Tellegen, A. (1988). Development and validation of brief measures of positive and negative affect: The PANAS scales. Journal of Personality and Social Psychology, 54(6), 1063-1070.

Publisher's Note Springer Nature remains neutral with regard to jurisdictional claims in published maps and institutional affiliations. 